\title{
Total Phenolic and Flavonoid Contents, Antioxidant and Antimicrobial Activities of Traditional Unripe Grape Products
}

\author{
Filiz Ucan Turkmen ${ }^{1 *}$, Hatice Aysun Mercimek Takci ${ }^{2}$, Nazım Sekeroglu ${ }^{3}$ \\ ${ }^{1}$ Food Engineering, Kilis 7 Aralık University, Kilis, TURKEY \\ ${ }^{2}$ Molecular Biology and Genetics, Kilis 7 Aralık University, Kilis, TURKEY \\ ${ }^{3}$ Medicinal and Aromatic Plants Program, Kilis 7 Aralık University, Kilis, TURKEY
}

\begin{abstract}
Unripe grape products, unripe grape juice (or koruk juice), unripe grape powder and unripe grape piece are common condiments in Kilis traditional cousin. Besides their taste roles, their probable health benefits were also studied in this work. To evaluate total phenolic and flavonoid contents, antioxidant capacity and antimicrobial activity of unripe grape samples (juice, powder and piece) extracted by various solvents. Samples were extracted separately by ethanol and distilled water $(10 \%)$. Concentrated samples were suspended in methanol to final concentration $100 \mathrm{mg} / \mathrm{mL}$. Percentage yield in the extracts were observed to range from 4.19 to 17.76 . While the total phenolic contents of ethanol and distilled water extracts were revealed to range from 505.682 to 758.523 and 424.432 to $603.409 \mathrm{mg} \mathrm{GAE} / \mathrm{g}$; total flavonoid contents of extracts were 0.073 to 0.147 and 0.041 to $0.055 \mathrm{mgRE} / \mathrm{g}$, respectively. Antioxidant capacity of extracts was calculated between 64.07 (ethanol) and $82.64 \%$ (distilled water). Studied extracts showed antimicrobial activity against only one test microorganism, C. albicans. The highest antibacterial activity $(8 \mathrm{~mm})$ was observed in unripe grape piece distilled water extract.
\end{abstract}

KEY WORDS: Phenolic, Flavonoid, Antioxidant, Antimicrobial, Unripe Grape

\section{INTRODUCTION}

Grapes (Vitisvinifera) belong to family Vitaceae $^{1}$ andare of the most widely grown fruit in Kilis district. Koruk is locally called as unripen grape and have been processed into various traditional flavoring and condiment products, such as unripe grape juice (or koruk juice), unripe grape powder and unripe grape piece in Kilis located in eastern Mediterranean region of Turkey. Unripe grape is also known as "vertjus" or "verjus" in French, "verjons" or "verjuice" in English, "agraz" in Spanish and German, "agresto" in Italian, "koruk" in Turkish and "abe-ghureh" in Persian", Koruk is the immature form of the grape fruit. It has high acidity, sour taste; low $\mathrm{pH}$, low sugar and high phenolic contend. ${ }^{4}$ Koruk juice has been used as a food ingredient and as a medicine since ancient Greeks. In medieval and early modern times koruk juice has been used as an acidifying agent in cooking, as medicine and as digestive agent.Koruk juice has a tart taste and a strong acidity. It is commonly used with salad and vegetables as an acidifying and flavoring agent in Turkey and neighboring countries. It is also consumed as a drink after being sweetened. ${ }^{5,6}$ Koruk and its juice have high antioxidant property because of its phenolic profiles. Moreover, these are sources of organic acid and have antimicrobial effects. ${ }^{7}$ Koruk juice, Verjuice, is used as an alternative to vinegar and lemon juice. ${ }^{2}$ It is produced and consumed locally, particularly in the Mediterranean, Southeastern regions of Turkey, and many different regions of Iran. It has been used to augment
DOI: 10.5530/ijper.51.3s.72 Correspondence: Filiz Ucan Turkmen, Food Engineering, Kilis 7 Aralik, University, Kilis, TURKEY

Contact:

+903488142666/1812

E-Mail: ucanfiliz@gmail.com 
the flavor of traditional meals, salads, and appetizers, and as an ingredient in the production of various drinks and several sausages such as mustard sausage. ${ }^{3}$ Unripe grape juice is used to reduce blood pressure and cholesterol as well as maintaining the body weight in traditional medicine. ${ }^{8}$ Ahmadi andRoney ${ }^{9}$ reported that specifically, the effects of verjuice supplementation on serum lipid profile, blood pressure, inflammatory markers, endothelial function, oxidation, glycemic control, and fatty streak formation have been evaluated with in vivo and human randomized control trials. Therefore, through these mechanisms, verjuice may be a useful dietary agent for the prevention and treatment of Cardiovascular Disease (CVD).Increasing demand of natural and functional products by consumers has directed research toward to new alternatives. Unripe grape products have gained popularity in the recent years and could be a good alternative with their physicochemical and antioxidant properties.Phenolic compounds in grape juice, grape seed and wine have been investigated by many researchers to show their potent antioxidant, antimutagenic, antibacterial, antiviral, antifungal and antiulcer activities. However, little information is available on the effect of ethanol and distilled water extracts on the percentage yield, total phenolic, total flavonoids, antioxidant activity and antimicrobial activity of unripe grape samples. The purpose of this study was to compare the effects of ethanol and distilled water extracts on the overall qualities in unripe grape samples. The quality criteria evaluated included: studies on the percentage yield, total phenolic, total flavonoids, antioxidant activity and antimicrobial activity.

\section{MATERIAL AND METHODS}

In this study, unripe grape samples were purchased from in Kilis located in eastern Mediterranean region of Turkey. Samples (unripe grape juice -koruk juice-, unripe grape powder and unripe grape piece) were extracted separately by ethanol and distilled water $(10 \%)$. Concentrated samples were suspended in methanol to final concentration $100 \mathrm{mg} / \mathrm{mL}$.About $10 \mathrm{~g}$ of the powdered materials were extracted in ethanol and distilled water $(250 \mathrm{~mL})$ by using the Soxhlet apparatus. Following filtration of the final extracts, they were concentrated under vacuum on a rotary evaporator at $35^{\circ} \mathrm{C}$. Dry extracts were dissolved in $5 \mathrm{~mL}$ of methanol. Samples prepared in either methanol or ethanol according to the type of the extract. The following terms were used to describe the different treatments in our study: E1 (Koruk juice-ethanol), E2 (Koruk piece-ethanol), E3 (Koruk powder-ethanol), DW1 (Koruk juice-distilled water), DW2 (Koruk piece- distilled water), DW3 (Koruk powder- distilled water). All treatments and analysis were carried out in triplicates. Samples were stored at $4^{\circ} \mathrm{C}$ for further use.

Total Phenolic Contents: The concentration of total phenolic in extracts was measured by using spectrophotometric method. $0.5 \mathrm{~mL}$ of the methanolic or ethanolic extracts was mixed with $2.5 \mathrm{~mL}$ of $10 \%$ Folin-Ciocalteu's

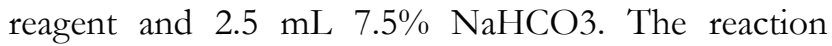
mixtures were incubated in a water bath at $45^{\circ} \mathrm{C}$ for 45 min. Thereafter, the absorbance of samples was spectrophotometrically measured at $765 \mathrm{~nm}$. A standard curve was prepared by using standard Gallic Acid solution in different concentrations. The content of phenolics in extracts was expressed as Gallic Acid Equivalent $(\mathrm{mg} / \mathrm{L})$, according to the measured absorbance. ${ }^{10}$

Total flavonoid contents: The total flavonoid content of extracts was determined by the aluminum chloride colorimetric method (catechol as a standard). In brief, $1 \mathrm{ml}$ of test sample was diluted (1:6) and mixed with $0.3 \mathrm{ml} \% 5 \mathrm{NaNO}_{2}$. Then the mixture was mixed with a vortex and thereafter was incubated for $5 \mathrm{~min}$. At the end of time, $0.6 \mathrm{~mL}$ of $10 \% \mathrm{AlCl}_{3} 6 \mathrm{H}_{2}$ Osolution was added and after incubated ( $5 \mathrm{~min}$ ), the obtained reaction mixture by adding $2 \mathrm{~mL}$ of $1 \mathrm{M} \mathrm{NaOHsolution} \mathrm{was}$ brought to $10 \mathrm{~mL}$ with double-distilled water. The mixture was allowed to stand for $15 \mathrm{~min}$, and absorbance was measured at $510 \mathrm{~nm}$ with UV-VIS spectrophotometer (Biochrom, Libra S60, B, and England). The total flavonoid content was calculated from a calibration curve and the result was expressed as $\mathrm{mg} / \mathrm{L}$ catechol. ${ }^{11}$

DPPH Radical Scavenging Assay: The antioxidant capacity of the extracts was determined by the stable DPPH (2,2-diphenyl 1-picrylhydrazyl) radical scavenging assay. $100 \mu \mathrm{L}$ of the extracts and $3.9 \mathrm{~mL}$ of the DPPH $(0.025 \mathrm{~g} / \mathrm{L}$ in methanol) solution prepared in either methanol or ethanol according to the type of the extract were mixed. The mixtures were incubated in dark at room temperature for $2 \mathrm{~h}$. The remaining DPPH amount was determined by measuring at $515 \mathrm{~nm}$ absorbance. In test extracts, the inhibition of DPPH was calculated as percent according to the formula $\mathrm{I} \%=[(\mathrm{A}$ blank $-\mathrm{A}$ sample $) /$ Ablank $] \times 100$. The blank is the absorbance of the control, which contains all reagents except the extract, and A sample is the absorbance of the test extract or the reference. ${ }^{12,13}$

Antibacterial Activity: Antibacterial activity of unripe grape sample extracts against three bacteria (Staphylococcus aureus, Candida albicansandEscherichia coli) was investigated by the agar well diffusion method. The standard antibacterial agent, Tetracycline $(10 \mu \mathrm{g} /$ disc $)$ and the pure methanol were used as control groups. 
Statistical Analysis: The software SPSS 20.0 for Windows (SPSS Inc. Chicago, IL, USA) was used for analysis of variance (ANOVA) and Duncan's multiple comparison tests inorder to determine significant differences between the samples. Each experiment was repeated at least three times. Statistical analysis was evaluated between samples which obtained from same solvents.

\section{RESULTS AND DISCUSSION}

Total phenolic and flavonoid contents, antioxidant activity and antimicrobial activity of unripe grape samples (juice, powder and piece) extracted by ethanol and distilled water solvents were determined in this work and the results were given in the Table 1 and Figure 1. As seen in the Table 1, percentage yields in the extracts ranged from 4.19 to 17.76. Compared to ethanol and distilled water extracts, the highest values were determined in E1 and DW2 as 13.05 and $17.76 \%$, respectively. Jayaprakasha et al. ${ }^{14}$ reported that extract yield in yield of grape seed extracts for methanol extract were determined as 8.1 (\% dry grape seeds). Results obtained for the total phenolic and flavonoidcontentss and DPPH radical scavenging assay of extracts ethanol and distilled water in unripe grape samples are depicted in Table 1.

The phenolic compounds mainly include anthocyanins, flavonols, stableness (resveratrol) and phenolic acids. ${ }^{1}$ While the total phenolic contents of ethanol and distilled water extracts were revealed to range from 505.682 to 758.523 and 424.432 to $603.409 \mathrm{mg} \mathrm{GAE} / \mathrm{g}$, the total flavonoid contents of extracts were 0.073 to 0.147 and 0.041 to $0.055 \mathrm{mg} \mathrm{RE} / \mathrm{g}$, respectively. Antioxidant capacity of extracts was calculated between 64.07 (ethanol) and $82.64 \%$ (distilled water). For these three analysis,

\begin{tabular}{|c|c|c|c|}
\hline $\begin{array}{l}\text { Analysis I } \\
\text { Extracts }\end{array}$ & $\begin{array}{l}\text { Total flavonoid } \\
\text { (mg RE/g) }\end{array}$ & $\begin{array}{c}\text { Total phenolic } \\
\text { content } \\
\text { (mg GAE/g) }\end{array}$ & $\begin{array}{c}\text { DPPH } \\
\text { (Inhibition \%) }\end{array}$ \\
\hline \multicolumn{4}{|l|}{ Ethanol } \\
\hline E1 & $0.14^{\mathrm{a}}$ & $758.52^{\mathrm{a}}$ & $79.77^{b}$ \\
\hline E2 & $0.07^{\mathrm{b}}$ & $505.68^{c}$ & $79.71^{b}$ \\
\hline E3 & $0.076^{b}$ & $596.02^{b}$ & $64.07^{d}$ \\
\hline \multicolumn{4}{|l|}{$\begin{array}{l}\text { Distilled } \\
\text { water }\end{array}$} \\
\hline DW1 & $0.04^{d}$ & $603.40^{\mathrm{b}}$ & $68.88^{c}$ \\
\hline DW2 & $0.04^{d}$ & $424.43^{d}$ & $82.14^{\mathrm{ab}}$ \\
\hline DW3 & $0.05^{c}$ & $436.36^{d}$ & $82.64^{a}$ \\
\hline
\end{tabular}

Values followed by different superscripted letter within the same column are significantly different from each other $(p<0.05)$.
E1 $\square$ E2 $\square$ E3 $\square$ DW $\square$ DW2 $\square$ DW3

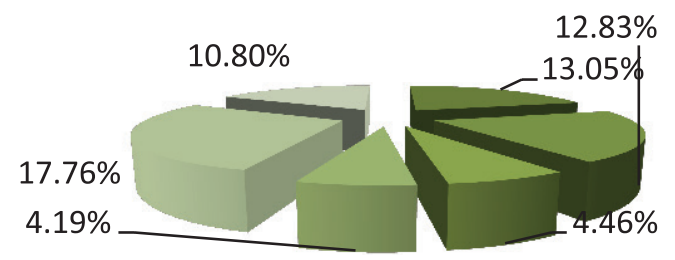

Figure 1: Effects of different extracts on percentage yield of unripe grape samples

the differences of between ethanol and distilled water extracts were found to be statistically significant $(\mathrm{p}<0.05)$. In ethanol extracts of unripe grape juice samples, total phenolics were found to be the highest $(758.52 \mathrm{mg}$ $\mathrm{GAE} / \mathrm{g})$. However, in ethanol extracts of unripe grape pieces samples were found to be the lowest $(505.68 \mathrm{mg}$ $\mathrm{GAE} / \mathrm{g}$ ). In distilled water extracts of unripe grape juice samples, total phenolic content were found to be the highest (603.40 mg GAE/g). However; in distilled water extracts of unripe grape pieces samples were found to be the lowest (424.43 $\mathrm{mg} \mathrm{GAE} / \mathrm{g}$ ).

Öncül and Karabiyıkl1 ${ }^{15}$ found that total phenol content of koruk (American Rootstock) was $652.13 \mathrm{mg} / \mathrm{L} . \mathrm{Ahn}$ et al. ${ }^{16}$ reported that total tannin in grape seed extract were $535.64 \mathrm{mg} / 100 \mathrm{~g}$.Baydar et al. ${ }^{17}$ reported that total phenolic content extracted by different solvent mixtures ranged from 627.98 to $667.87 \mathrm{mg}$ GAE/g in grape seed extracts. In ethanol extracts of unripe grape juice samples, total flavonoid content was found to be the highest $(0.14 \mathrm{mg} \mathrm{RE} / \mathrm{g})$. However, in ethanol extracts of unripe grape pieces samples were found to be the lowest (0.07 mg RE/g). In distilled water extracts of unripe grape powder samples, total phenolic content were found to be the highest ( $0.05 \mathrm{mg} \mathrm{RE} / \mathrm{g}$ ).Jayaprakasha et al. ${ }^{14}$ reported that total flavonol for methanol extract were determined as 16.0 (in catechin equivalents $/ 100 \mathrm{~g}$ extract). In ethanol extracts of unripe grape juice samples, DPPH (\% inhibition) were found to be the highest $(79.77 \%)$. However, in ethanol extracts of unripe grape powder were found to be the lowest (64.07\%). When comes to the distilled water, the highest and the lowest values were determined to unripe grape powder $(82.64 \%)$ and unripe grape juice samples (68.88\%), respectively.Ahn et al. ${ }^{16}$ reported that DPPH (\% inhibition) in grape seed extract were found as $86.98 \%$.

Table 2 presents antimicrobial activity against only one test microorganism, C. albicans of sample extracts. Sample extracts showed antimicrobial activity against only one test microorganism, C. albicans. The highest antibacterial activity $(8 \mathrm{~mm})$ was observed in grape piece distilled water extract. The extracts of Vitisvinifera seed exhibited 
Table 2: Antimicrobial activity against test microorganisms of sample extracts

\begin{tabular}{|c|c|c|c|}
\hline \multirow{2}{*}{ Extracts } & \multicolumn{3}{|c|}{ Microorganisms } \\
\cline { 2 - 4 } & E.coli & S. aureus & C. albicans \\
\hline Ethanol & & & \\
\hline E1 & 8 & 10 & - \\
\hline E2 & 9 & 9 & 7 \\
\hline E3 & - & - & - \\
\hline Distilled water & & & \\
\hline DW1 & 9 & 10 & 7 \\
\hline DW2 & - & 10 & 8 \\
\hline DW3 & 9 & 8 & - \\
\hline Methanol & 8 & 10 & - \\
\hline Tetrascycline & 11 & 29 & - \\
\hline
\end{tabular}

antimicrobial activity to some pathogens such as Staphylococcus aureus, Escherichia coli and Candida albicans. ${ }^{18}$

\section{CONCLUSION}

For ethanol extracts, the highest total phenolic and flavonoid contents, antioxidant activity and percentage yield in unripe grape juices were revealed. But in distilled water extracts, while the highest total phenolic content and antioxidant activity were detected in unripe grape powder, the maximum total phenolic content was in unripe grape juice extract. Besides their flavor and condiment uses of the koruk products, it could be said that they are good for human health. As traditional food additives and flavorings, koruk products should be evaluated as natural food flavoring agents in the healthy food industry.

\section{ACKNOWLEDGEMENTS}

This reported work was pursued in Kilis 7 Aralik University and the authors acknowledge the entire laboratory and other essential facilities provided.

\section{CONFLICT OF INTEREST STATEMENT}

The authors declare that there is no conflict of interests regarding the publication of this paper.

\section{ABBREVIATION USED}

E1: (Koruk juice-ethanol); E2: (Koruk piece-ethanol); E3: (Koruk powder-ethanol); DW1: (Koruk juice-dis- tilled water); DW2: (Koruk piece distilled water); DW3: (Koruk powder- distilled water).

\section{REFERENCES}

1. Ahmad W, Khan MI, Waqar M, Khan MA, Akram Khan RR, Wali S, et al. In vitro antibacterial activity of Vitisvinifera leaf extracts against some pathogenic bacterial strains. Advances in Biological Research. 2014;8(2):62-7.

2. Aminian B, Massoompour SM, Sadeghalvaad A, Omrani GH. Unripe grape juice (verjuice) as a lipid-lowering agent: fact or fiction. Archives of Iranian Medicine. 2003;6(1):32-4.

3. Alipour M, Davoudi P, Davoudi Z. Effects of unripe grape juice (verjuice) on plasma lipid profile, blood pressure, malondialdehyde and total antioxidant capacity in normal, hyperlipidemic and hyperlipidemic with hypertensive human volunteers. Journal of Medicinal Plants Research. 2012;6(45):5677-83.

4. Winkler AJ. General Viticulture-University of California Press, Berkeley and Losangeles. 1965.

5. Karapınar M, Sengun IY. Antimicrobial effect of koruk (unripe grapeVitisvinifera) juice against Salmonella typhimurium on salad vegetables. Food Control. 2007;18(6):702-6.

6. Güler A, Tokuşoğlu Ö. Production of Koruk Juice Concentrate and Determination of the Effects of the Process on Quality and Antioxidan Activity. 25th International Scientific-Experts Congress on Agriculture and Food Industry Izmir, Turkey. 2014;117-20.

7. Güler A, Tokuşoğlu, Ö. Quality Evaluation, Total Phenolic Content, Organic Acid Profiles and Antioxidant Activity of Soft Drinks with Koruk (Sour Grape) Concentrate. Natural Science and Discovery. 2016;2(2):41-7.

8. Çevik M, Tezcan D, Sabancı S, İçier F. Changes in Rheological Properties of Koruk (Unripe Grape) Juice Concentrates During Vacuum Evaporation. Vacuum. 2016;7-13.

9. Ahmadi L, Roney SK. Pharmacological and Phytochemical Properties of Unripe Grape Juice (Verjuice): A Review. Austin Journal of Nutrition \& Metabolism. 2014;1(2):9.

10. Stanković MS. Total Phenolic Content, Flavonoid Concentration and antioxidant Activity of Marrubiumperegrinum L. Extracts. Kragujevac J Sci. 2011;33(2011):63-72.

11. Sharm S, Vig PA. Evaluation of In vitro Antioxidant Properties of Methanol and Aqueous Extracts of Parkinsoniaaculeata L. Leaves. The Scientific World Journal. 2013;1-7.

12. Huang $D$, Ou B, Prior RL. The chemistry behind antioxidant capacity assays. J Agric Food Res 2005;53(6):1841-56.

13. YIImaz OM. Determination of The Antioxidant Activity and Phenolic Acid Composition of Main Wheat Varieties Grown in Turkey and Enrichment of Bread with Pomegranate Husk Extract. PhD Thesis. Ankara University, 2011;pp 80.

14. Jayaprakasha GK, Singh RP, Sakariah KK. Antioxidant activity of grape seed (Vitisvinifera) extracts on peroxidation models in vitro. Food chemistry. 2001;73(3):285-90.

15. Öncül N, Karabiyikli Ş. Factors Affecting the Quality Attributes of Unripe Grape Functional Food Products. Journal of Food Biochemistry. 2015;39(6):689-95.

16. Ahn HS, Jeon TI, Lee JY, Hwang SG, Lim Y, Park DK. Antioxidative activity of persimmon and grape seed extract: in vitro and in vivo. Nutrition Research. 2002;22(11):1265-73.

17. Baydar NG, Ozkan G, Sagdıc O. Total phenolic contents and antibacterial activities of grape (Vitisvinifera L.) extracts. Food Control. 2004;15(5):335-9.

18. Papadopoulou C, Soulti K, Roussis IG. Potential antimicrobial activity of red and white wine phenolic extracts against strains of Staphylococcus aureus, Escherichia coliand Candidaalbicans. Food Technology and Biotechnology. 2005;43(1):41-6. 


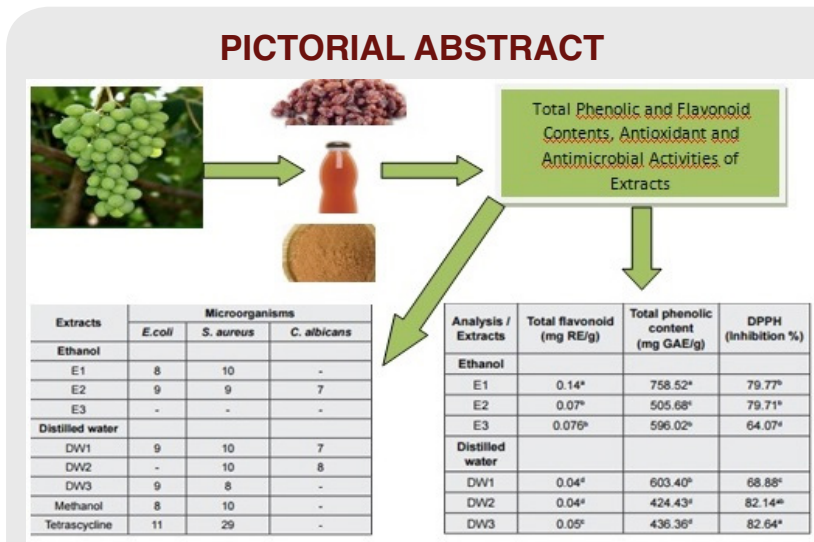

ABOUT AUTHORS

\section{SUMMARY}

- Unripe grape products are common condiments in Kilis traditional cousin.

- Samples were extracted separately by ethanol and distilled water $(10 \%)$.

- Antioxidant capacity of extracts was calculated between 64.07(ethanol) and $82.64 \%$ (distilled water).

- The total phenolic contents of ethanol and distilled water extracts were revealed to range from 505.682 to 758.523 and 424.432 to $603.409 \mathrm{mg}$ $\mathrm{GAE} / \mathrm{g}$.

- The total flavonoid contents of extracts were 0.073 to 0.147 and 0.041 to $0.055 \mathrm{mgRE} / \mathrm{g}$

- Studied extracts showed antimicrobial activity against only one test microorganism, C. albicans.

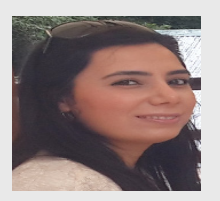

Filiz Ucan Turkmen: Food Engineering, Kilis 7 Aralik University, Kilis, Turkey.

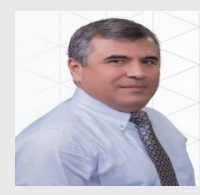

Nazim Sekeroglu: Medicinal and Aromatic Plants Program, Kilis 7 Aralik University, Kilis, Turkey

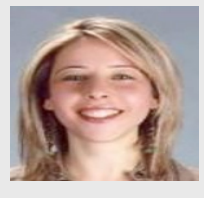

Hatice Aysun Mercimek Takci: Molecular Biology and Genetics, Kilis 7 Aralik University, Kilis, Turkey.

Cite this article: Ucan Turkmen F, Mercimek Takci HA, Sekeroglu N. Total Phenolic and Flavonoid Contents, Antioxidant and Antimicrobial Activities of Traditional Unripe Grape Products. Indian J of Pharmaceutical Education and Research. 2017;51(3)Suppl:S489-93. 